\title{
REVIEW
}

\section{The clinical characteristics of dementia with Lewy bodies and a consideration of prodromal diagnosis}

\author{
Paul C Donaghy ${ }^{*}$ and lan G McKeith
}

\begin{abstract}
Dementia with Lewy bodies (DLB) is the second most common type of degenerative dementia following Alzheimer's disease (AD). DLB is clinically and pathologically related to Parkinson's disease (PD) and PD dementia, and the three disorders can be viewed as existing on a spectrum of Lewy body disease. In recent years there has been a concerted effort to establish the phenotypes of $A D$ and PD in the prodromal phase (before the respective syndromes of cognitive and motor impairment are expressed). Evidence for the prodromal presentation of DLB is also emerging. This paper briefly reviews what is known about the clinical presentation of prodromal DLB before discussing the pathology of Lewy body disease and how this relates to potential biomarkers of prodromal DLB. The presenting features of DLB can be broadly placed in three categories: cognitive impairment (particularly nonamnestic cognitive impairments), behavioural/psychiatric phenomena (for example, hallucinations, rapid eye movement sleep behaviour disorder (RBD)) and physical symptoms (for example, parkinsonism, decreased sense of smell, autonomic dysfunction). Some noncognitive symptoms such as constipation, RBD, hyposmia and postural dizziness can predate the onset of memory impairment by several years in DLB. Pathological studies of Lewy body disease have found that the earliest sites of involvement are the olfactory bulb, the dorsal motor nucleus of the vagal nerve, the peripheral autonomic nervous system, including the enteric nervous system, and the brainstem. Some of the most promising early markers for DLB include the presence of RBD, autonomic dysfunction or hyposmia, ${ }^{123}$-metaiodobenzylguanidine cardiac scintigraphy, measures of substantia nigra pathology and skin biopsy for a-synuclein in peripheral autonomic nerves. In the absence of disease-modifying therapies, the diagnosis of prodromal DLB is of limited use in the clinic. That said, knowledge of the prodromal development of DLB could help clinicians identify cases of DLB where the diagnosis is uncertain. Prodromal diagnosis is of great importance in research, where identifying Lewy body disease at an earlier stage may allow researchers to investigate the initial phases of dementia pathophysiology, develop treatments designed to interrupt the development of the dementia syndrome and accurately identify the patients most likely to benefit from these treatments.
\end{abstract}

\section{Introduction}

Dementia with Lewy bodies (DLB) is the second most common type of degenerative dementia following Alzheimer's disease (AD). DLB accounts for around $4.2 \%$ of all dementia diagnosed in the community, and $7.5 \%$ of those under secondary care [1]. The characteristic features of DLB are spontaneous parkinsonism, recurrent visual hallucinations, fluctuating cognition, rapid eye movement sleep behaviour disorder (RBD), severe sensitivity to

\footnotetext{
* Correspondence: paul.donaghy@ncl.ac.uk

Level 3, Biomedical Research Building, Institute for Ageing and Health,

Campus for Ageing and Vitality, Newcastle University, Newcastle NE4 5PL, UK
}

antipsychotic medications and reduction in striatal dopamine transporters on single photon emission computed tomography (SPECT) or positron emission tomography (PET) (Figure 1) [2]. The pattern of neuropsychological deficits seen in DLB is different to those in AD, with less marked memory impairment and more severe impairments of visuospatial, attentional and frontal-executive function [3].

The clinical features of DLB and Parkinson's disease dementia (PDD) are similar [2,4]. Based on international consensus, DLB is diagnosed when cognitive impairment precedes parkinsonism or begins within a year of parkinsonism. 


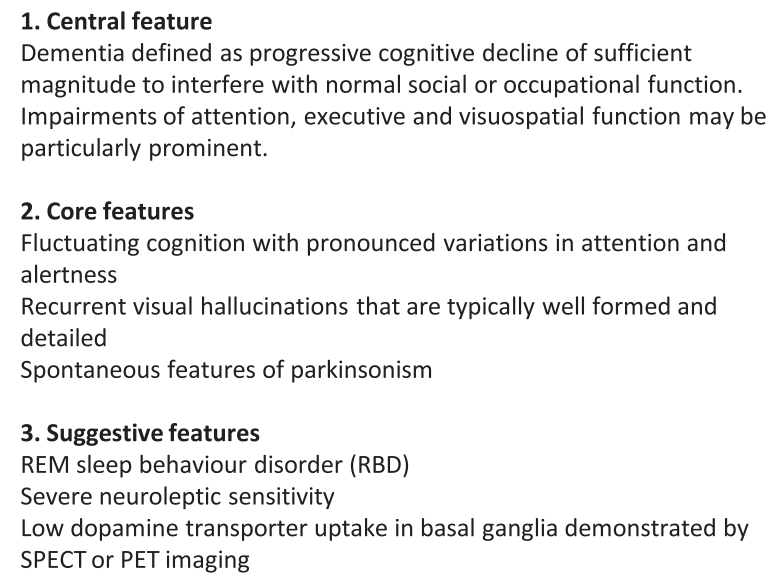

2. Core features

Fluctuating cognition with pronounced variations in attention and alertness

Recurrent visual hallucinations that are typically well formed and detailed

Spontaneous features of parkinsonism

\section{Suggestive features}

REM sleep behaviour disorder (RBD)

Severe neuroleptic sensitivity

Low dopamine transporter uptake in basal ganglia demonstrated by SPECT or PET imaging

For a diagnosis of probable or possible DLB, dementia must be present.

Probable DLB: at least one core feature and one other feature (core or suggestive)

Possible DLB: one core feature and no suggestive features; or one or more suggestive features

\section{Supportive features (commonly present but not proven to have diagnostic accuracy) \\ Repeated falls and syncope \\ Transient, unexplained loss of consciousness \\ Severe autonomic dysfunction, e.g., orthostatic hypotension, urinary incontinence \\ Hallucinations in other modalities \\ Systematized delusions \\ Depression \\ Relative preservation of medial temporal lobe structures on $\mathrm{CT} / \mathrm{MRI}$ scan \\ Generalized low uptake on SPECT/PET perfusion scan with reduced occipital activity \\ Abnormal (low uptake) MIBG myocardial scintigraphy \\ Prominent slow wave activity on EEG with temporal lobe transient sharp waves}

Figure 1 Diagnostic criteria for dementia with Lewy bodies. $C T$, computed tomography; DLB, dementia with Lewy bodies; EEG, electroencephalogram; MRI, magnetic resonance imaging; MIBG, metaiodobenzylguanidine; PET, positron emission tomography; REM, rapid eye movement; SPECT, single photon emission computed tomography. Adapted from [2]

PDD is diagnosed when parkinsonism precedes cognitive impairment by more than 1 year (Figure 2) [2]. DLB and PDD are now recognised in the Diagnostic and Statistical Manual of Mental Disorders, where they are respectively coded as 'Major and Mild Neurocognitive Disorder with Lewy Bodies' and as 'Major and Mild Neurocognitive Disorder due to Parkinson's Disease' [5].

As with Parkinson's disease (PD) and PDD, the main pathological lesions seen in DLB are Lewy bodies (LBs) and Lewy neurites, both containing $\alpha$-synuclein ( $\alpha$ Syn) [6]. The pattern of distribution of LB pathology in DLB, PD and PDD as seen at end stage is very similar, although cortical involvement may occur earlier in DLB and brainstem involvement may be minimal [7-9]. The three disorders can be viewed as existing on a spectrum of LB disease [10], suggesting that studies of symptom development and pathology in PD, although not identi$\mathrm{cal}$, are probably highly relevant to any consideration of the early stages of DLB.

In recent years there has been a concerted effort to establish the phenotypes of $\mathrm{AD}$ and $\mathrm{PD}$ in the prodromal phase, which is defined as the period between the onset of the earliest symptoms and the development of the full clinical syndrome. Evidence of the prodromal presentation of DLB is also emerging [11]. Criteria for the clinical diagnosis of DLB have high specificity but low sensitivity [12]. In the move towards earlier diagnosis, biomarkers of LB disease may be necessary to optimise diagnostic accuracy. This paper briefly considers what is known about the clinical presentation of prodromal DLB before discussing the pathology of LB disease and how this relates to potential biomarkers of prodromal DLB. The paper will then discuss how this knowledge can be applied to current clinical and research practice.

\section{Symptoms of prodromal dementia with Lewy bodies} The presenting features of DLB can be broadly placed in three categories (Figure 3): cognitive impairment; behavioural/psychiatric phenomena; and physical symptoms.

\section{Cognitive impairment}

Mild cognitive impairment (MCI) is conceived as a state intermediate between normal cognitive function and dementia [13]. People with MCI are at increased risk of developing dementia [14], leading to MCI being considered a prodromal phase of dementia [15]. A proportion of MCI cases that convert to dementia may develop DLB, although rates have varied from around 5\% to around 25\% across different studies [16-19]. Some of this variation is likely to be due to recruitment criteria for the studies; for example, amnestic MCI largely from primary care, 5.6\% DLB [17]; MCI from a tertiary referral centre, $28.4 \%$ DLB [18]. DLB can be preceded by amnestic or nonamnestic cognitive impairment, although cases involving nonmemory domains (that is, attention/executive, visuospatial or language) are more likely to progress to DLB than single-domain amnestic MCI $[19,20]$.

Fluctuating attention and cognition is a core feature of DLB [2], but evidence so far suggests that fluctuations are the least common core symptom in the prodromal phase (present in $2 / 7$ cases [21] and $3 / 9$ cases [22] in two longitudinal studies). Delirium and transient disturbances of consciousness, however, are reported as prodromal features of DLB and may represent the earliest manifestations of cognitive fluctuation [23].

\section{Behavioural/psychiatric phenomena}

Importantly, DLB may initially present with noncognitive symptoms such as visual hallucinations, depression 


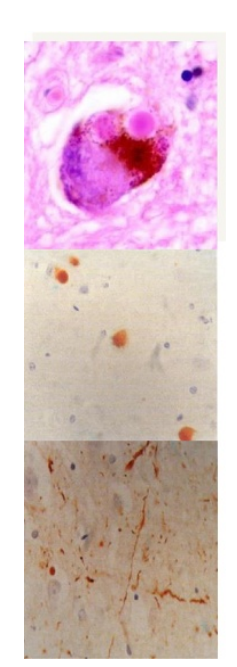

\section{Lewy Body Disease}

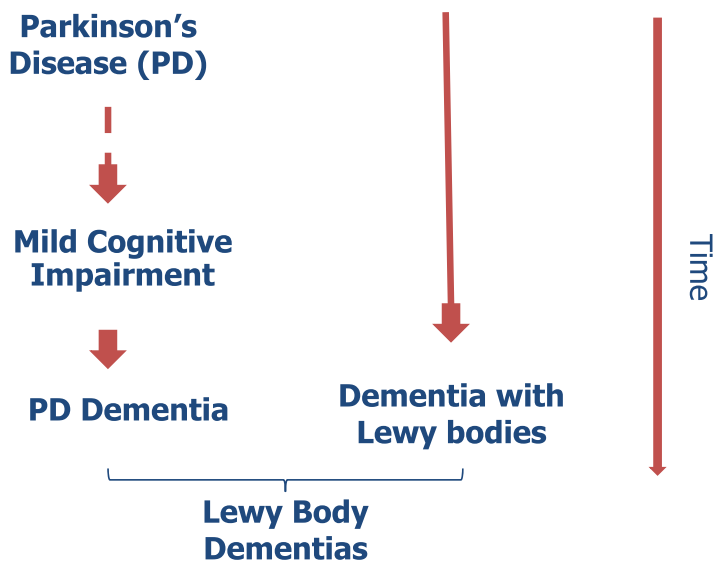

Figure 2 Nomenclature of Lewy body diseases. Parkinson's disease dementia is diagnosed when cognitive impairment develops a year or more after the onset of parkinsonism. Dementia with Lewy bodies is diagnosed when cognitive symptoms appear without parkinsonism or less than 1 year after the onset of parkinsonism.

and RBD [24]. RBD is a parasomnia characterised by the enactment of dreams (for example, punching, kicking, shouting out) that often results in injury. Longitudinal studies of RBD have shown that up to $93 \%$ of cases go on to develop a synucleinopathy - PD, PDD, DLB or

\section{Cognitive}

Non-amnestic cognitive impairments Cognitive fluctuations (less common)

\section{Psychiatric / behavioural}

REM sleep behaviour disorder

Visual hallucinations

Depression

Delirium

\section{Physical}

Parkinsonism

Hyposmia

Constipation

\section{Orthostatic hypotension}

Figure 3 Examples of presenting symptoms of dementia with Lewy bodies. REM, rapid eye movement. multiple system atrophy, a clinically and pathologically distinct non-LB synucleinopathy [25] - if followed up for a sufficient number of years [26-28].

Retrospective studies have found that visual hallucinations and RBD can be present in around one-half of DLB cases prior to or around the onset of memory loss $[24,29,30]$. Anxiety and depression were present in around one-quarter of patients [24,29]. Retrospective case-control studies have found that a history of depression [31] or delirium [23] prior to the diagnosis of dementia is more common in DLB than AD, although both delirium and depression are probably too common in the normal older person to be useful biomarkers in isolation.

\section{Physical symptoms}

Parkinsonism is a core feature of DLB, and may be a presenting symptom in around one-quarter of patients [24]. $\alpha$ Syn deposition in the olfactory bulb, brainstem and peripheral nervous system in LB disorders is associated with a variety of physical symptoms, such as decreased sense of smell (hyposmia), constipation, orthostatic dizziness and increased salivation [24].

Some noncognitive symptoms of DLB such as constipation, hyposmia and postural dizziness can predate the onset of memory impairment by years in DLB [29]. In the earliest clinical phase of DLB, patients may therefore be expected to present with one or, more probably, a combination of these symptoms in mild form. Based on the presence of these symptoms one could suppose that a person has prodromal LB disease, even in the absence of cognitive dysfunction, but given that these are 
common complaints in older people, they are in themselves likely to be very nonspecific predictors. Given this nonspecificity, a combination of several symptoms along with other biomarkers may be necessary to identify those with prodromal DLB.

\section{Neuropathology of dementia with Lewy bodies}

Prior to any discussion of the probable biomarkers of prodromal DLB, the temporal development of LB pathology must be considered. Much of the work on the pathology of LB disease comes from research in PD. Just over a decade ago, Braak and colleagues proposed a staging system for Lewy pathology in PD [32]. In a sample of brains from PD patients and asymptomatic individuals with LB disease, they found that all could be classified into one of six stages of disease development. At the earliest stage (stage 1), LB pathology was confined to the dorsal motor nucleus of cranial nerves IX/X and the intermediate reticular zone of the medulla. Over the subsequent stages, LB pathology ascended sequentially through the pons, midbrain and subcortical structures to finally affect the neocortex itself in stages 5 and 6 (Figure 4). A key feature of Braak staging was that the sequential ascent of LB pathology from the brainstem to the neocortex was common to all cases - that is, the cortex was not involved in every case; but where the cortex was affected, so were lower structures such as the limbic system and brainstem. Others have observed that LB pathology does not necessarily follow this pattern of distribution, particularly when cases are sampled from the general population, in which LB pathology can be

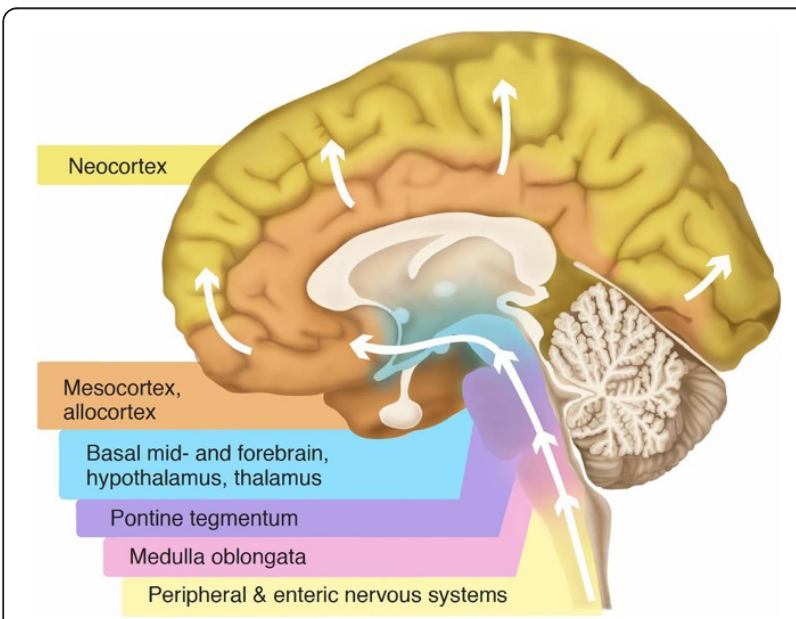

Figure 4 Progression of Lewy body pathology. Schematic diagram of the pattern of alpha-synuclein deposition as hypothesised by Braak and colleagues [32]. Deposition is first seen in the peripheral autonomic nervous system, including the enteric nervous system. This is then followed by deposition in the brainstem, ascending to the limbic system and, finally, the neocortex. Illustration from [88], available under creative commons license. found in higher centres such as the neocortex, despite sparing of lower regions [7,33-35]. Nevertheless, it is clear that some structures are particularly susceptible to LB pathology and may potentially act as sentinels for the development of LB disease: the olfactory bulb [7], the dorsal motor nucleus of the vagal nerve and other brainstem structures [32] and the peripheral autonomic nervous system [36,37], including the enteric nervous system [38].

The pattern of deposition of Lewy pathology in DLB cases seen at autopsy is similar to that of PD/PDD $[7,8]$. Dementia is the clinical expression of widespread and relatively advanced brain disease. Unsurprisingly, then, the majority of DLB cases are found to have an advanced Braak stage, with cortical involvement $[7,8]$. The actual amount of cortical LB pathology does not necessarily correlate with clinical dementia severity [39], and significant cortical pathology can occur in the absence of clinical symptoms $[33,40]$. One explanation for this is that LBs do not directly cause cell dysfunction and death. Presynaptic accumulation of $\alpha$ Syn and resultant synaptic dysfunction has been put forward as a causative factor of neurodegeneration in LB disease but, like LB deposition, this cannot yet be measured in vivo [41].

Postmortem examination of brains from people who suffered from DLB is informative to a degree about the pathology of the later stages of disease, but less so about the earlier stages of disease development. Findings from studies of early PD and LB disease without any clinical symptoms (incidental LB disease) may be used to hypothesise about the early pathological development of DLB.

Incidental LB disease with cortical involvement has been suggested to be more likely to progress to DLB than PD [33]. If so, the profile of structural and functional brain changes that can be detected in vivo during the prodromal phases of LB disease will probably also vary between DLB and PD, reflecting differences in the underlying pathology. Some pathological differences between DLB and PDD have been identified [42]. DLB is associated with higher amyloid plaque deposition in the striatum $[43,44]$, more frequent $\alpha$ Syn deposition in the CA2/3 area of the hippocampus [45] and significantly higher $5-\mathrm{HT}_{1 \mathrm{~A}}$ receptor density in the frontal cortex [46]. Compared with PD, DLB demonstrates less marked cell loss in the substantia nigra, and a relative lack of $D_{2}$ receptor upregulation in the striatum [47].

Although LB pathology is the pathological hallmark of DLB, other types of pathology may interact with LB pathology, or may potentially mimic the DLB phenotype in the absence of significant LB pathology. In community-based cohorts, dementia is most often associated with mixed pathology including $\mathrm{AD}$, vascular and LB pathology [48]. $\mathrm{MCI}$ in PD is associated with heterogeneous pathology 
[42]. Coexisting LB and AD pathology (amyloid-beta $(A \beta)$ and tau) is frequently found in DLB at postmortem $[49,50]$. The importance of AD pathology in DLB is not yet clear. In amyloid PET imaging studies, LB disease groups have lower mean amyloid ligand binding than $\mathrm{AD}$ groups. Many cases have normal levels of amyloid binding, although amyloid deposition is more common in DLB than PDD and is relatively rare in PD, suggesting that A $\beta$ may be associated with an increased risk of dementia in $\mathrm{LB}$ disease [51]. The presence of AD pathology may reduce the likelihood of expression of the typical DLB phenotype [52,53]. In some cases of LB disease, LBs are predominantly confined to the amygdala [54]. This pattern of deposition is common in $\mathrm{AD}$, and may represent a different clinicopathologic process to PD/PDD/DLB $[7,55]$.

\section{A hypothetical biomarker profile of prodromal dementia with Lewy bodies}

Jack and colleagues put forward a model of dynamic biomarkers for $\mathrm{AD}$, with markers of $\mathrm{A} \beta$ deposition sequentially followed by markers of tau-mediated neuronal injury and dysfunction, changes in brain structure, abnormalities in tests of memory and, finally, a decline in day-to-day function [56]. This hypothesis has been criticised due to emerging evidence against the amyloid cascade hypothesis [57]. Nevertheless, the idea of a process beginning with abnormal protein deposition followed by cell damage or death and then loss of function is a useful conceptual base from which to consider the likely development of biomarkers in DLB (Figure 5A). DLB is associated with a relative lack of structural brain changes compared with $\mathrm{AD}$ [58] and structural change can be presumed to be less likely and therefore harder to detect in the earliest stages of disease. The additional effects of Alzheimer pathology may well operate to a greater or lesser extent in many subjects but these have not been incorporated into the schematic.

The process of abnormal protein deposition-cell damage-functional decline will occur at different times in different areas (Figure 5B), with both the peripheral and central nervous systems involved early in DLB. For example, measureable loss of function may occur in the olfactory system before significant protein deposition has occurred in higher cortical areas. The following paragraphs examine possible biomarkers of protein deposition, cell damage and functional decline to assess their potential usefulness in prodromal DLB in relation to what is known about the pathology of LB disease.

\section{Biomarkers of protein deposition}

In vivo measurement of $\mathrm{A} \beta$, the putative pathological hallmark of $\mathrm{AD}$, is possible with cerebrospinal fluid $\mathrm{A} \beta$

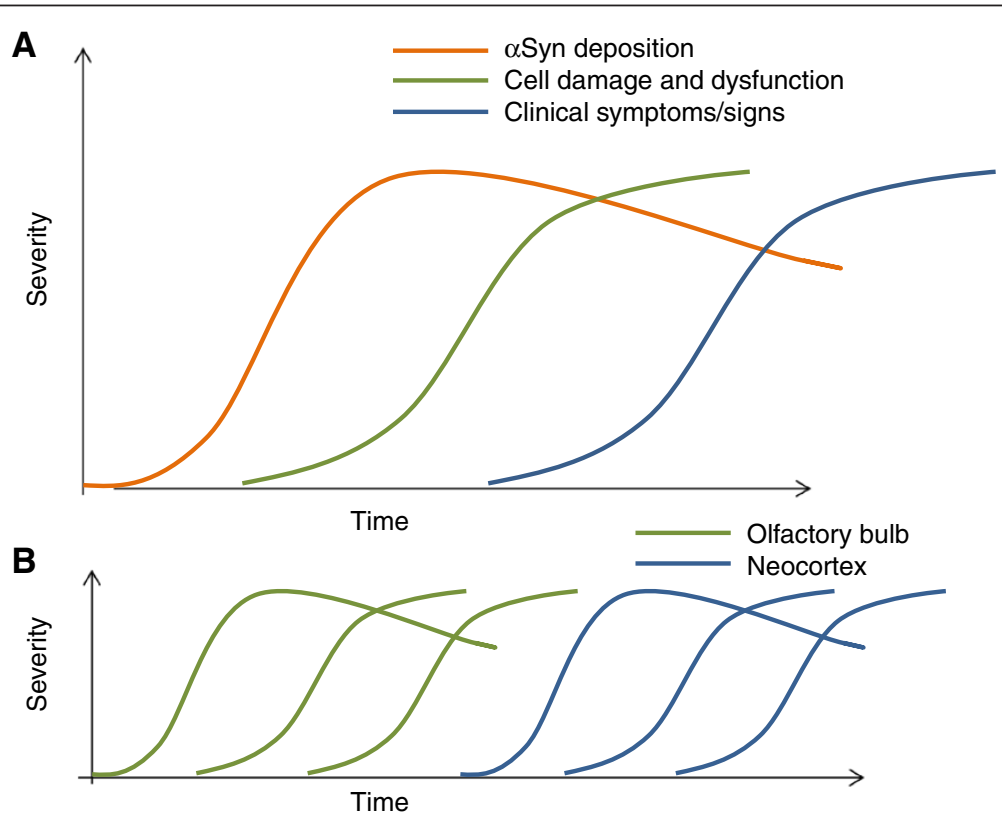

Figure 5 Hypothetical timelines of biomarker development. (A) Biomarker development in dementia with Lewy bodies (DLB). This hypothesis mirrors that proposed by Jack and colleagues in Alzheimer's disease [56]. The first biomarkers of DLB will be markers of alpha-synuclein (aSyn) deposition (for example, from skin biopsy). aSyn deposition probably decreases later in the disease process following cell death [40]. This would then be followed by markers of cell damage or death (for example, loss of dopamine transporters in the striatum on single photon emission computed tomography or positron emission tomography) and then clinical symptoms/signs (for example, parkinsonism). (B) Biomarkers in two different sites. In this hypothetical representation, aSyn deposition, cell damage and loss and the development of symptoms (hyposmia) all occur in the olfactory bulb prior to the development of aSyn deposition in the neocortex. 
levels and amyloid PET imaging. No radioligands are yet available to image $\alpha$ Syn in vivo, although some are in development [59]. Several studies have found reduced cerebrospinal fluid $\alpha$ Syn in established DLB, although other studies have found no such differences [60]. This heterogeneity of results may reflect methodological differences in the measurement of $\alpha$ Syn, or cerebrospinal fluid contamination with red blood cells, which are relatively rich in $\alpha$ Syn [60]. The utility of blood and cerebrospinal fluid biomarkers in the diagnosis of DLB remains unresolved. There has been no research into the use of such markers in the prodromal stage of DLB.

Some of the earliest sites of LB deposition include the olfactory bulb $[7,32]$ and the enteric nervous system $[38,61]$. Biopsies from these sites are a possible route to detect $\alpha$ Syn deposition in vivo $[62,63]$ with potential for early diagnosis, although the invasiveness of these techniques could limit their application [64].

More recently, Wang and colleagues used a new technique to measure the proportion of peripheral autonomic nerve fibres containing $\alpha$ Syn in skin biopsies [65]. In a sample of patients with PD and controls, $\alpha$ Syn was detected in all subjects but rates in the PD group were markedly higher [65]. The difference was less marked in those with mild disease, although it remained significant. The sampling and processing techniques used in this study were more sensitive than previous techniques, detecting $\alpha$ Syn even in controls, suggesting a threshold rather than absolute biomarker potential.

\section{Biomarkers of cell death or dysfunction}

\section{${ }^{123}$ I-metaiodobenzylguanidine cardiac scintigraphy}

Specialised imaging techniques are already in use to detect cell death and dysfunction in neural systems particularly vulnerable in LB disease. Cardiac ${ }^{123}$ I-metaiodobenzylguanidine (MIBG) scintigraphy uses a noradrenaline analogue to identify presynaptic sympathetic nerve terminals in the heart. This technique can detect cardiac sympathetic denervation that is associated with LB disorders.

In one study, seven asymptomatic individuals had abdominal or pelvic autonomic plexuses removed during surgery (generally for oncologic disease) and examined for the presence of $\alpha$ Syn. Later, the patients underwent ${ }^{123}$ I-MIBG cardiac scintigraphy and a striatal dopamine transporter scan. All four $\alpha$ Syn-positive patients had an abnormal cardiac MIBG scan, compared with none of the $\alpha$ Syn-negative patients. Conversely, only one of four $\alpha$ Syn-positive patients and no $\alpha$ Syn-negative patients had a positive ${ }^{123} \mathrm{I}-\mathrm{N}$ - $\omega$-fluoropropyl-2 $\beta$-carbomethoxy$3 \beta$-(4-iodophenyl)nortropane SPECT scan [37]. Two cases of DLB have been reported with abnormal ${ }^{123} \mathrm{I}-$ MIBG cardiac scintigraphy during the MCI phase of the illness [66]. However, cardiac MIBG uptake can be abnormal in congestive cardiac failure, ischaemic heart disease and diabetic autonomic neuropathy, potentially limiting its usefulness, particularly in older people [67].

\section{Biomarkers of substantia nigra pathology}

Cell death in the substantia nigra can be assessed by measuring nigrostriatal dopaminergic innervation of the striatum using PET or SPECT with a radiolabelled dopamine analogue ( $N$ - $\omega$-fluoropropyl-2 $\beta$-carbomethoxy-3 $\beta$ (4-iodophenyl)nortropane) (Figure 6). The substantia nigra is a relatively early site of LB deposition (stage 3 in the Braak system) [32] and dopaminergic depletion in the striatum might be anticipated to be a sensitive indicator of early LB disease. However, three of 27 patients with MCI followed-up for 3 years developed DLB, and only one of these had a positive striatal dopamine transporter scan at baseline [68]. Another patient with a positive scan developed frontotemporal dementia. This observation is consistent with the late or minimal involvement of brainstem dopaminergic projection neurones in many DLB cases and suggests that the optimal time point for dopamine transporter imaging may be in established rather than prodromal disease.

Another marker of substantia nigra pathology is enlarged hyperechogenicity on ultrasound. Of 1,535 healthy adults that had baseline substantia nigra ultrasonography and completed follow up, 11 developed PD. Eight of these cases had substantia nigra hyperechogenicity, compared with $18 \%$ of the rest of the sample [69]. In an RBD group, 2/43 patients developed DLB. Both had substantia nigra hyperechogenicity at baseline, and one also had reduced striatal dopamine transporters on SPECT imaging [70].

\section{Other biomarkers of cell dysfunction or death}

Two longitudinal studies following MCI subjects found that DLB subjects had heterogeneous patterns of cortical hypometabolism on ${ }^{18}$ F-fluorodeoxyglucose PET during the MCI phase, but not the occipital hypometabolism that best differentiates established DLB from AD [71,72]. Fujishiro and colleagues followed a case series of 10 nondemented patients that had attended their memory clinic and were found to have baseline occipital hypometabolism [73]. Four converted to probable DLB, and one to possible DLB; all of these had baseline RBD.

Cortical atrophy is less marked in DLB compared with $\mathrm{AD}$, and therefore is unlikely to be prominent early in the disease [58]. In three autopsy-confirmed DLB patients that had serial magnetic resonance imaging during the MCI phase, hippocampal volumes and rates of hippocampal atrophy were within the range of cognitively normal subjects [21].

\section{Clinical biomarkers of functional decline}

In $\mathrm{AD}$, loss of function - detected by neuropsychological tests or reported by the patient - is expected to appear 


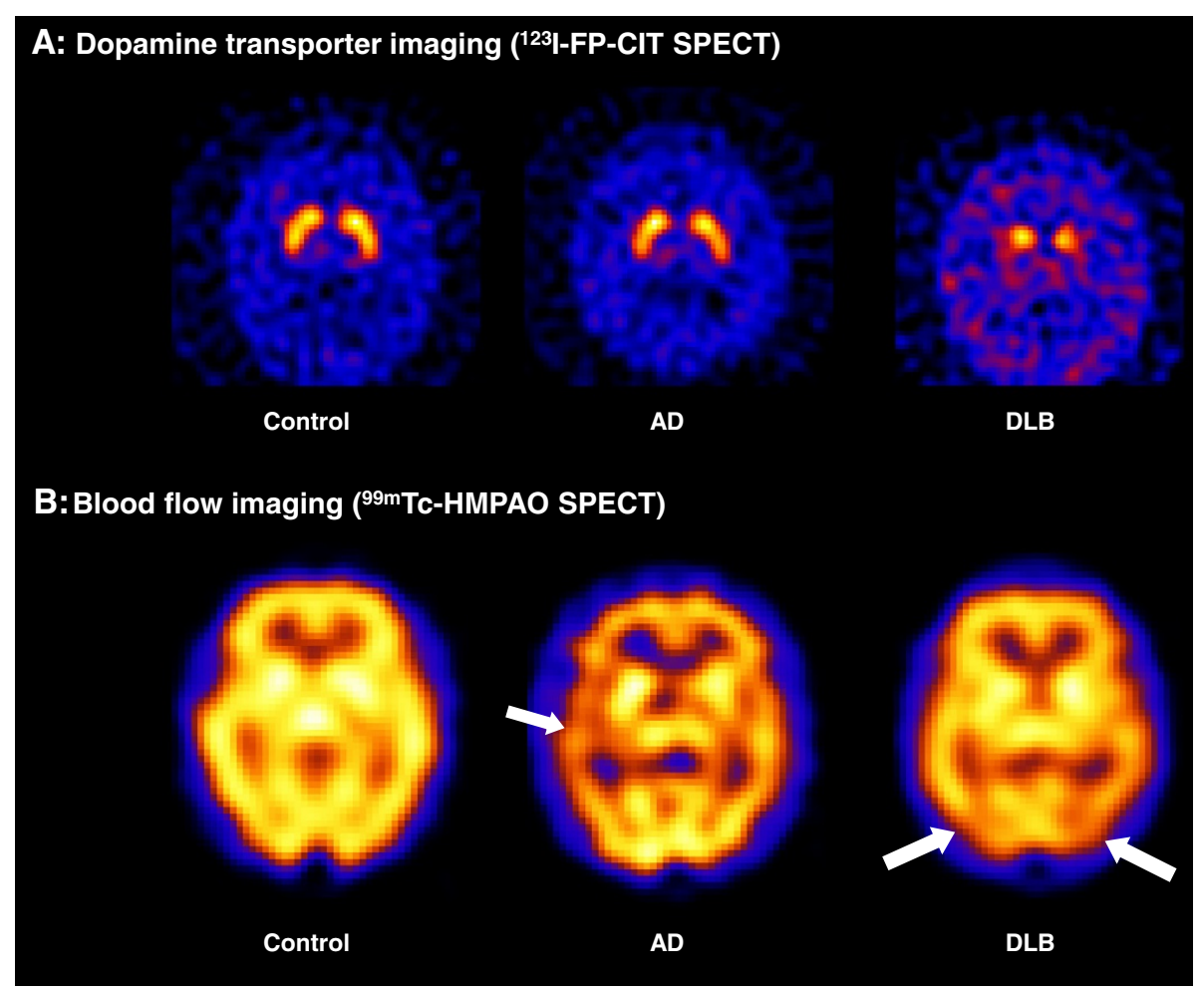

Figure 6 Examples of imaging abnormalities in dementia with Lewy bodies. (A) Dopamine transporter imaging. Both the control and Alzheimer's disease (AD) subjects display normal dopamine transporter levels in the striatum. The dementia with Lewy bodies (DLB) subject displays reduced uptake in the putamen bilaterally, reflecting nigrostriatal degeneration. (B) Cerebral blood flow imaging. The AD subject shows decreased perfusion compared with control, particularly in the left temporal lobe. The DLB subject also exhibits perfusion deficits, but these are

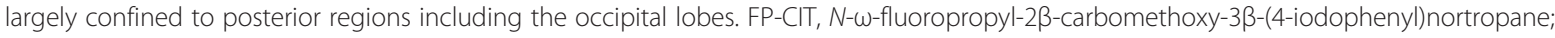
HMPAO, exametazime; SPECT, single photon emission computed tomography.

at the end of the process of protein deposition, cell damage and structural change. Due to the specific topographical development of LB pathology, loss of function in structures affected early in the disease can actually precede the earliest pathological changes in other brain areas (Figure 5B). Damage to the olfactory bulb, the enteric nervous system and midbrain nuclei can lead to anosmia, constipation and RBD, respectively. All of these symptoms have been reported to occur several years before the onset of memory impairment in PD [74] and DLB $[29,30]$. However, since DLB has an older age of onset than PD, 'normal' subjects will be more likely to have symptoms such as constipation, minor motor abnormalities and postural hypotension. This may decrease the specificity of individual clinical biomarkers in prodromal DLB, which may best be described by a pattern of symptoms accumulating over time.

There has been little investigation of clinical biomarkers in MCI cohorts followed up for DLB. One group has intensively studied a cohort with RBD, a population at risk of subsequent development of full-blown LB disease. They found that those with RBD who developed PD or DLB had evidence at baseline of greater postural fall in blood pressure [75], minor motor abnormalities [76] and worse colour vision and olfactory function [77], although not electrocardiographic measures of cardiac autonomic dysfunction [78]. In PD, large cohorts have failed to link later development of PD with baseline orthostatic hypotension or heart-rate variability [36]. The ${ }^{13} \mathrm{C}$-breath test is a measure of delayed gastric emptying that is abnormal even in early PD [79] and could be a marker of prodromal LB disease, although this has not yet been investigated.

Discovering the true clinical accuracy of symptoms and biomarkers in identifying prodromal DLB is only achievable through further prospective research to determine whether a cumulative risk score or profile could distinguish prodromal LB disease cases from normal controls and other dementia prodromes.

A staged approach may be necessary, beginning with bedside screening to identify those that may have LB disease by assessing for markers of functional decline - using symptom questionnaires, cognitive tests and simple clinical biomarkers (for example, biomarkers for hyposmia). In the second stage, those with a profile suggestive of LB disease would undergo tests with greater specificity, identifying death or dysfunction of cell groups affected by LB 
pathology, or the presence of $\alpha$ Syn pathology. These might include cardiac MIBG scintigraphy, striatal dopamine transporter imaging or a biopsy for the presence of $\alpha$ Syn (Figure 7). The aim of such a process would be to identify cases of prodromal DLB with high sensitivity and specificity, whilst minimising the use of invasive and expensive tests.

Evidence supporting the presence of LB disease may need to be weighed against evidence for the presence of other diseases such as AD. However, amyloid deposition is often seen in DLB [51], and DLB can develop from amnestic MCI [17]. The presence of amnestic MCI and a positive amyloid PET scan, sufficient for a diagnosis of 'prodromal $\mathrm{AD}$ ' or of 'MCI due to $\mathrm{AD}$ - intermediate likelihood' $[80,81]$, is therefore also consistent with prodromal DLB.

\section{Issues in prodromal dementia with Lewy bodies research Methodological issues}

Research into prodromal DLB is still in its early phase. There are some difficulties in studying an entity that has not yet been clearly defined. Retrospective studies of patients with DLB are helpful for assessing symptom development, but these may be susceptible to recall bias and are of limited use in assessing the real clinical utility of biomarkers of prodromal DLB. Longitudinal studies are needed for this, but existing longitudinal studies of unselected MCI groups generally have relatively small numbers of patients that convert to DLB, making such research prohibitively expensive and limiting the conclusions that can be drawn and generalised.

To ameliorate this problem, longitudinal studies need to select at-risk groups. Cohorts of RBD patients are already being investigated in this way [82]. Corresponding cohorts could also be selected based on the presence of other symptoms known to be associated with LB disease, such as hallucinations, parkinsonism or fluctuations, or the presence of nonamnestic cognitive impairments. Examining biomarker and symptom profiles over time in such groups will greatly increase our knowledge of prodromal DLB. In a virtuous cycle, such research will help to refine criteria for identifying at risk groups for subsequent studies.

One must keep in mind that groups with early development of symptoms such as RBD are likely to represent specific subgroups with patterns of disease development that are not necessarily common to all cases of prodromal DLB [83]. It is clear that some cases of DLB develop core features only later in the disease, if at all [84];

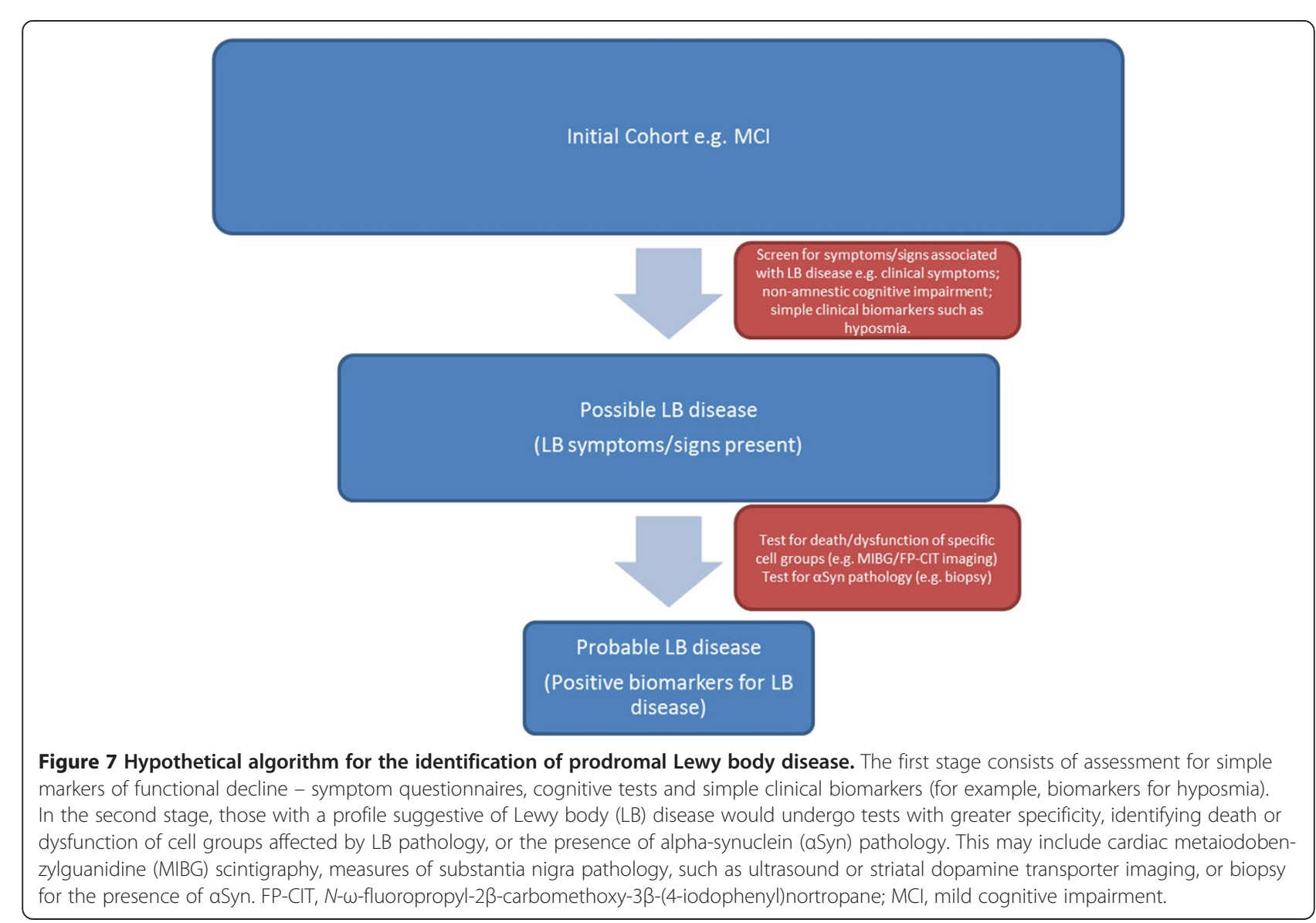


these patients may be particularly difficult to identify in the prodromal phase.

\section{Diagnostic issues}

The presence of symptoms associated with LB disease, such as RBD, hyposmia and autonomic dysfunction, along with early biomarkers of LB disease may allow the identification of people who suffer from LB disease prior to the development of cognitive or motor symptoms. DLB is differentiated from PDD on the basis that cognitive features develop before or within a year of parkinsonism. In the move toward earlier diagnosis, the identification of slight parkinsonian signs and mild cognitive difficulties prior to the development of any full clinical syndrome makes such distinctions more difficult. The distinction between DLB and PDD is unlikely to be useful or practicable at this stage and a general classification of 'prodromal LB disease' may be more appropriate. Different patterns of biomarkers may possibly emerge as predictors of which patients will progress to develop particular clinical presentations over time.

At present, in the absence of disease-modifying therapies, identifying LB disease prior to the development of cognitive or motor dysfunction has little obvious clinical benefit. However, enquiring about prodromal symptoms may be most helpful in current clinical practice when the clinician is endeavouring to establish the cause of dementia in a patient who already has mild, moderate or even severe impairment but in whom the subtype diagnosis remains unclear. Enquiry about prodromal symptoms, particularly but not restricted to RBD, can be extremely informative in signposting a DLB diagnosis that can be further substantiated with use of a biomarker appropriate to that stage of disease.

\section{Conclusions}

There is a growing belief that by the time dementia has developed, sufficient brain damage has occurred to prevent any disease-modifying treatment working effectively. The identification of prodromal dementia allows researchers to investigate the initial phases of dementia pathophysiology, develop treatments designed to interrupt the development of the dementia syndrome and accurately identify the patients most likely to benefit from these treatments.

Prior to the availability of such treatments, it is not clear that a clinical diagnosis of prodromal dementia is useful to patients or their clinicians [85]. The European Union Joint Action on Alzheimer's Initiative recently provided recommendations on the timely diagnosis of dementia [86]. Timely diagnosis here reflects access to diagnosis at a time when people can use this information to make sense of what is happening to them, make lifestyle changes and plan for the future' [86]. Timely diagnosis may thus change when new information or treatments become available. At present, diagnosis of DLB in the early stages of dementia would seem more timely and appropriate than an earlier diagnosis of prodromal LB disease of uncertain prognosis. That said, knowledge of the prodromal development of DLB could help clinicians identify cases of DLB where the diagnosis is uncertain.

For the DLB research community, the diagnosis of prodromal DLB is an area of growing interest, providing an important opportunity to investigate the earliest stages of LB disorders. Such efforts are already underway in RBD [82] and prospective cohorts based upon other risk profiles need to be similarly studied.

Further characterisation of biomarkers confirming the presence of LB pathology has been identified as a priority for LB disease research [87] and is a necessary prerequisite for conducting clinical trials of emerging prevention agents. The widespread deposition of $\alpha$ Syn pathology in DLB may prove key in prodromal diagnosis. Based on current evidence and the temporal development of LB pathology, some of the most promising early biological markers include ${ }^{123}$ I-MIBG cardiac scintigraphy, skin biopsy and measures of substantia nigra pathology. Over the coming years, longitudinal studies should establish which of these markers are most effective. In parallel with this, such studies will help to uncover the early pathophysiology of LB disease, aiding the development of treatment and prevention strategies.

Note: This article is part of a series on Lewy Body Dementia, edited by lan McKeith and James Galvin. Other articles in this series can be found at http://alzres.com/series/LewyBodyDementia.

\section{Abbreviations}

Aß: amyloid beta; AD: Alzheimer's disease; aSyn: alpha-synuclein; DLB: dementia with Lewy bodies; LB: Lewy body; MCl: mild cognitive impairment; MIBG: metaiodobenzylguanidine; PD: Parkinson's disease; PDD: Parkinson's disease dementia; PET: positron emission tomography; RBD: rapid eye movement sleep behaviour disorder; SPECT: single photon emission computed tomography.

\section{Competing interests}

The authors declare that they have no competing interests.

\section{Acknowledgements}

This work was supported by the National Institute for Health Research (NIHR) Newcastle Biomedical Research Unit based at Newcastle upon Tyne Hospitals NHS Foundation Trust and Newcastle University. The views expressed are those of the authors and not necessarily those of the National Health Service, the NIHR or the Department of Health.

The authors thank Dr Sean Colloby for kindly providing illustrations of ${ }^{99 m} \mathrm{Tc}$ exametazime and ${ }^{123} \mid-N$ - $\omega$-fluoropropyl-2 $\beta$-carbomethoxy-3 $\beta$-(4-iodophenyl) nortropane SPECT imaging.

Published: 21 Jul 2014 


\section{References}

1. Vann Jones SA, O'Brien JT: The prevalence and incidence of dementia with Lewy bodies: a systematic review of population and clinical studies. Psychol Med 2014, 44:673-683.

2. McKeith IG, Dickson DW, Lowe J, Emre M, O'Brien JT, Feldman H, Cummings J, Duda JE, Lippa C, Perry EK, Aarsland D, Arai H, Ballard CG, Boeve B, Burn DJ, Costa D, Del Ser T, Dubois B, Galasko D, Gauthier S, Goetz CG, Gomez-Tortosa E, Halliday G, Hansen LA, Hardy J, Iwatsubo T, Kalaria RN, Kaufer D, Kenny RA, Korczyn A, et al: Diagnosis and management of dementia with Lewy bodies. Neurology 2005, 65:1863-1872.

3. Metzler-Baddeley C: A review of cognitive impairments in dementia with Lewy bodies relative to Alzheimer's disease and Parkinson's disease with dementia. Cortex 2007, 43:583-600.

4. Emre M, Aarsland D, Brown R, Burn DJ, Duyckaerts C, Mizuno Y, Broe GA, Cummings J, Dickson DW, Gauthier S, Goldman J, Goetz C, Korczyn A, Lees A, Levy R, Litvan I, McKeith I, Olanow W, Poewe W, Quinn N, Sampaio C, Tolosa E, Dubois B: Clinical diagnostic criteria for dementia associated with Parkinson's disease. Mov Disord 2007, 22:1689-1707. quiz 1837.

5. American Psychiatric Association: Diagnostic and Statistical Manual of Mental Disorders. 5th edition. Arlington, VA: American Psychiatric Publishing; 2013.

6. Jellinger KA: Formation and development of Lewy pathology: a critical update. J Neurol 2009, 256(Suppl 3):270-279.

7. Beach TG, Adler CH, Lue L, Sue LI, Bachalakuri J, Henry-Watson J, Sasse J, Boyer S, Shirohi S, Brooks R, Eschbacher J, White CL 3rd, Akiyama H, Caviness J, Shill HA, Connor DJ, Sabbagh MN, Walker DG, Arizona Parkinson's Disease Consortium: Unified staging system for Lewy body disorders: correlation with nigrostriatal degeneration, cognitive impairment and motor dysfunction. Acta Neuropathol 2009, 117:613-634

8. Jellinger KA: Lewy body-related alpha-synucleinopathy in the aged human brain. J Neural Transm 2004, 111:1219-1235.

9. Halliday G, Hely M, Reid W, Morris J: The progression of pathology in longitudinally followed patients with Parkinson's disease. Acta Neuropathol 2008, 115:409-415.

10. McKeith I: Commentary: DLB and PDD: the same or different? Is there a debate? Int Psychogeriatr 2009, 21:220-224.

11. Donaghy P, O'Brien JT, Thomas A: Prodromal dementia with Lewy bodies. Psychol Med 2014, 1-10. Epub ahead of print. [http://journals.cambridge.org/ action/displayAbstract?fromPage=online\&aid=9223458\&fileld=S0033291714000816]

12. Nelson P, Jicha G, Kryscio R, Abner E, Schmitt F, Cooper G, Xu L, Smith C Markesbery W: Low sensitivity in clinical diagnoses of dementia with Lewy bodies. J Neurol 2010, 257:359-366.

13. Petersen RC, Smith GE, Waring SC, Ivnik RJ, Tangalos EG, Kokmen E: Mild cognitive impairment: clinical characterization and outcome. Arch Neurol 1999, 56:303-308.

14. Mitchell AJ, Shiri-Feshki M: Rate of progression of mild cognitive impairment to dementia - meta-analysis of 41 robust inception cohort studies. Acta Psychiatr Scand 2009, 119:252-265.

15. Petersen RC, Roberts RO, Knopman DS, Boeve BF, Geda YE, Ivnik RJ, Smith GE, Jack CR Jr: Mild cognitive impairment: ten years later. Arch Neurol 2009, 66:1447-1455.

16. Fischer $P$, Jungwirth $S$, Zehetmayer $S$, Weissgram $S$, Hoenigschnabl $S$, Gelpi E, Krampla W, Tragl KH: Conversion from subtypes of mild cognitive impairment to Alzheimer dementia. Neurology 2007, 68:288-291.

17. Palmqvist S, Hertze J, Minthon L, Wattmo C, Zetterberg H, Blennow K, Londos E, Hansson O: Comparison of brief cognitive tests and CSF biomarkers in predicting Alzheimer's disease in mild cognitive impairment: six-year follow-up study. PLoS One 2012, 7:e38639.

18. Bombois S, Debette S, Bruandet A, Delbeuck X, Delmaire C, Leys D, Pasquier F: Vascular subcortical hyperintensities predict conversion to vascular and mixed dementia in MCl patients. Stroke 2008, 39:2046-2051.

19. Ferman TJ, Smith GE, Kantarci K, Boeve BF, Pankratz VS, Dickson DW, Graff-Radford NR, Wszolek Z, Van Gerpen J, Uitti R, Pedraza O, Murray ME, Aakre J, Parisi J, Knopman DS, Petersen RC: Nonamnestic mild cognitive impairment progresses to dementia with Lewy bodies. Neurology 2013, 81:2032-2038

20. Jicha GA, Parisi JE, Dickson DW, Johnson K, Cha R, lvnik RJ, Tangalos EG Boeve BF, Knopman DS, Braak H, Petersen RC: Neuropathologic outcome of mild cognitive impairment following progression to clinical dementia. Arch Neurol 2006, 63:674-681.
21. Molano J, Boeve B, Ferman T, Smith G, Parisi J, Dickson D, Knopman D, Graff-Radford N, Geda Y, Lucas J, Kantarci K, Shiung M, Jack C, Silber M, Pankratz VS, Petersen R: Mild cognitive impairment associated with limbic and neocortical Lewy body disease: a clinicopathological study. Brain 2010, 133:540-556.

22. Jicha GA, Schmitt FA, Abner E, Nelson PT, Cooper GE, Smith CD, Markesbery WR: Prodromal clinical manifestations of neuropathologically confirmed Lewy body disease. Neurobiol Aging 2010, 31:1805-1813.

23. Vardy E, Holt R, Gerhard A, Richardson A, Snowden J, Neary D: History of a suspected delirium is more common in dementia with Lewy bodies than Alzheimer's disease: a retrospective study. Int J Geriatr Psychiatry 2014, 29:178-181.

24. Auning E, Rongve A, Fladby T, Booij J, Hortobagyi T, Siepel FJ, Ballard C, Aarsland D: Early and presenting symptoms of dementia with lewy bodies. Dement Geriatr Cogn Disord 2011, 32:202-208.

25. Ahmed Z, Asi YT, Sailer A, Lees AJ, Houlden H, Revesz T, Holton JL: The neuropathology, pathophysiology and genetics of multiple system atrophy. Neuropathol Appl Neurobiol 2012, 38:4-24.

26. Iranzo A, Tolosa E, Gelpi E, Molinuevo JL, Valldeoriola F, Serradell M, Sanchez-Valle R, Vilaseca I, Lomena F, Vilas D, Lladó A, Gaig C, Santamaria J: Neurodegenerative disease status and post-mortem pathology in idiopathic rapid-eye-movement sleep behaviour disorder: an observational cohort study. Lancet Neurol 2013, 12:443-453.

27. Postuma RB, Gagnon JF, Vendette M, Fantini ML, Massicotte-Marquez J, Montplaisir J: Quantifying the risk of neurodegenerative disease in idiopathic REM sleep behavior disorder. Neurology 2009, 72:1296-1300

28. Schenck $\mathrm{CH}$, Boeve BF, Mahowald MW: Delayed emergence of a parkinsonian disorder or dementia in $81 \%$ of older males initially diagnosed with idiopathic REM sleep behavior disorder (RBD): 16-year update on a previously reported series. Sleep Med 2013, 14:744-748.

29. Chiba Y, Fujishiro H, Iseki E, Ota K, Kasanuki K, Hirayasu Y, Satoa K: Retrospective survey of prodromal symptoms in dementia with Lewy bodies: comparison with Alzheimer's disease. Dement Geriatr Cogn Disord 2012, 33:273-281.

30. Fujishiro H, Iseki E, Nakamura S, Kasanuki K, Chiba Y, Ota K, Murayama N, Sato K: Dementia with Lewy bodies: early diagnostic challenges. Psychogeriatrics 2013, 13:128-138.

31. Boot BP, Orr CF, Ahlskog JE, Ferman TJ, Roberts R, Pankratz VS, Dickson DW, Parisi J, Aakre JA, Geda YE, Knopman DS, Petersen RC, Boeve BF: Risk factors for dementia with Lewy bodies: a case-control study. Neurology 2013, 81:833-840.

32. Braak H, Del Tredici K, Rub U, de Vos RA, Jansen Steur EN, Braak E: Staging of brain pathology related to sporadic Parkinson's disease. Neurobiol Aging 2003, 24:197-211.

33. Frigerio R, Fujishiro H, Ahn TB, Josephs KA, Maraganore DM, DelleDonne A Parisi JE, Klos KJ, Boeve BF, Dickson DW, Ahlskog JE: Incidental Lewy body disease: do some cases represent a preclinical stage of dementia with Lewy bodies? Neurobiol Aging 2011, 32:857-863.

34. Zaccai J, Brayne C, McKeith I, Matthews F, Ince PG: Patterns and stages of alpha-synucleinopathy: relevance in a population-based cohort. Neurology 2008, 70:1042-1048.

35. Parkkinen L, Kauppinen T, Pirttila T, Autere JM, Alafuzoff I: Alpha-synuclein pathology does not predict extrapyramidal symptoms or dementia. Ann Neurol 2005, 57:82-91.

36. Palma JA, Kaufmann H: Autonomic disorders predicting Parkinson's disease. Parkinsonism Relat Disord 2014, 20(Suppl 1):S94-S98.

37. Minguez-Castellanos A, Chamorro CE, Escamilla-Sevilla F, Ortega-Moreno A, Rebollo AC, Gomez-Rio M, Concha A, Munoz DG: Do alpha-synuclein aggregates in autonomic plexuses predate Lewy body disorders? A cohort study. Neurology 2007, 68:2012-2018.

38. Braak H, de Vos RA, Bohl J, Del Tredici K: Gastric alpha-synuclein immunoreactive inclusions in Meissner's and Auerbach's plexuses in cases staged for Parkinson's disease-related brain pathology. Neuros $C$ Lett 2006, 396:67-72.

39. Marui W, Iseki E, Nakai T, Miura S, Kato M, Ueda K, Kosaka K: Progression and staging of Lewy pathology in brains from patients with dementia with Lewy bodies. J Neurol Sci 2002, 195:153-159.

40. Parkkinen L, Pirttila T, Alafuzoff I: Applicability of current staging/ categorization of alpha-synuclein pathology and their clinical relevance. Acta Neuropathol 2008, 115:399-407. 
41. Schulz-Schaeffer WJ: The synaptic pathology of alpha-synuclein aggregation in dementia with Lewy bodies, Parkinson's disease and Parkinson's disease dementia. Acta Neuropathol 2010, 120:131-143.

42. Jellinger KA: Neurobiology of cognitive impairment in Parkinson's disease. Expert Rev Neurother 2012, 12:1451-1466.

43. Halliday GM, Song YJ, Harding AJ: Striatal beta-amyloid in dementia with Lewy bodies but not Parkinson's disease. J Neural Transm 2011, 118:713-719.

44. Jellinger KA, Attems J: Does striatal pathology distinguish Parkinson disease with dementia and dementia with Lewy bodies? Acta Neuropathol 2006, 112:253-260.

45. Jellinger KA: Neuropathology of sporadic Parkinson's disease: evaluation and changes of concepts. Mov Disord 2012, 27:8-30.

46. Francis PT, Perry EK: Cholinergic and other neurotransmitter mechanisms in Parkinson's disease, Parkinson's disease dementia, and dementia with Lewy bodies. Mov Disord 2007, 22(Suppl 17):S351-S357.

47. Piggott MA, Marshall EF, Thomas N, Lloyd S, Court JA, Jaros E, Burn D, Johnson M, Perry RH, McKeith IG, Ballard C, Perry EK: Striatal dopaminergic markers in dementia with Lewy bodies, Alzheimer's and Parkinson's diseases: rostrocaudal distribution. Brain 1999, 122(Pt 8):1449-1468.

48. Schneider JA, Arvanitakis Z, Bang W, Bennett DA: Mixed brain pathologies account for most dementia cases in community-dwelling older persons. Neurology 2007, 69:2197-2204.

49. Lopez OL, Becker JT, Kaufer DI, Hamilton RL, Sweet RA, Klunk W, DeKosky ST: Research evaluation and prospective diagnosis of dementia with Lewy bodies. Arch Neurol 2002, 59:43-46.

50. Ballard C, Ziabreva I, Perry R, Larsen JP, O'Brien J, McKeith I, Perry E, Aarsland D: Differences in neuropathologic characteristics across the Lewy body dementia spectrum. Neurology 2006, 67:1931-1934.

51. Donaghy P, Thomas A, O'Brien JT: Amyloid PET imaging in Lewy body disorders. Am J Geriatr Psychiatry 2013. Epub ahead of print. [http://www. ajgponline.org/article/S1064-7481(13)00168-1/abstract]

52. Kraybill ML, Larson EB, Tsuang DW, Teri L, McCormick WC, Bowen JD, Kukull WA, Leverenz JB, Cherrier MM: Cognitive differences in dementia patients with autopsy-verified AD, Lewy body pathology, or both. Neurology 2005, 64:2069-2073.

53. Weisman D, Cho M, Taylor C, Adame A, Thal LJ, Hansen LA: In dementia with Lewy bodies, Braak stage determines phenotype, not Lewy body distribution. Neurology 2007, 69:356-359.

54. Leverenz JB, Hamilton R, Tsuang DW, Schantz A, Vavrek D, Larson EB, Kukull WA, Lopez O, Galasko D, Masliah E, Kaye J, Woltjer R, Clark C, Trojanowski JQ, Montine TJ: Empiric refinement of the pathologic assessment of Lewyrelated pathology in the dementia patient. Brain Pathol 2008, 18:220-224

55. Uchikado H, Lin WL, DeLucia MW, Dickson DW: Alzheimer disease with amygdala Lewy bodies: a distinct form of alpha-synucleinopathy. J Neuropathol Exp Neurol 2006, 65:685-697.

56. Jack CR Jr, Knopman DS, Jagust WJ, Shaw LM, Aisen PS, Weiner MW Petersen RC, Trojanowski JQ: Hypothetical model of dynamic biomarkers of the Alzheimer's pathological cascade. Lancet Neurol 2010, 9:119-128.

57. Fjell AM, Walhovd KB: Neuroimaging results impose new views on Alzheimer's disease - the role of amyloid revised. Mol Neurobiol 2012, 45:153-172.

58. Watson R, Blamire AM, O'Brien JT: Magnetic resonance imaging in lewy body dementias. Dement Geriatr Cogn Disord 2009, 28:493-506.

59. Yu L, Cui J, Padakanti PK, Engel L, Bagchi DP, Kotzbauer PT, Tu Z: Synthesis and in vitro evaluation of alpha-synuclein ligands. Bioorg Med Chem 2012 20:4625-4634

60. Kasuga K, Nishizawa M, Ikeuchi T: alpha-Synuclein as CSF and blood biomarker of dementia with Lewy bodies. Int J Alzheimers Dis 2012, 2012:437025.

61. Beach TG, Adler CH, Sue LI, Vedders L, Lue L, White lii CL, Akiyama H, Caviness JN, Shill HA, Sabbagh MN, Walker DG: Multi-organ distribution of phosphorylated alpha-synuclein histopathology in subjects with Lewy body disorders. Acta Neuropathol 2010, 119:689-702

62. Beach TG, White CL 3rd, Hladik CL, Sabbagh MN, Connor DJ, Shill HA, Sue LI, Sasse J, Bachalakuri J, Henry-Watson J, Akiyama H, Adler CH, Arizona Parkinson's Disease Consortium: Olfactory bulb alpha-synucleinopathy has high specificity and sensitivity for Lewy body disorders. Acta Neuropathol 2009, 117:169-174.

63. Shannon KM, Keshavarzian A, Mutlu E, Dodiya HB, Daian D, Jaglin JA, Kordower $\mathrm{JH}$ : Alpha-synuclein in colonic submucosa in early untreated Parkinson's disease. Mov Disord 2012, 27:709-715.
64. Parkkinen L, Silveira-Moriyama L, Holton JL, Lees AJ, Revesz T: Can olfactory bulb biopsy be justified for the diagnosis of Parkinson's disease? Comments on 'olfactory bulb alpha-synucleinopathy has high specificity and sensitivity for Lewy body disorders'. Acta Neuropathol 2009, 117:213-214. author reply 217-218.

65. Wang N, Gibbons CH, Lafo J, Freeman R: alpha-Synuclein in cutaneous autonomic nerves. Neurology 2013, 81:1604-1610.

66. Fujishiro H, Nakamura S, Kitazawa M, Sato K, Iseki E: Early detection of dementia with Lewy bodies in patients with amnestic mild cognitive impairment using ${ }^{123}$ I-MIBG cardiac scintigraphy. J Neurol Sci 2012, 315:115-119.

67. Chirumamilla A, Travin MI: Cardiac applications of ${ }^{123} \mathrm{I}-\mathrm{mIBG}$ imaging Semin Nucl Med 2011, 41:374-387.

68. Albin RL, Burke JF, Koeppe RA, Giordani B, Gilman S, Frey KA: Assessing mild cognitive impairment with amyloid and dopamine terminal molecular imaging. J Nucl Med 2013, 54:887-893.

69. Berg D, Behnke S, Seppi K, Godau J, Lerche S, Mahlknecht P, Liepelt-Scarfone I, Pausch C, Schneider N, Gaenslen A, Brockmann K, Srulijes K, Huber H, Wurster I, Stockner H, Kiechl S, Willeit J, Gasperi A, Fassbender K, Gasser T, Poewe W: Enlarged hyperechogenic substantia nigra as a risk marker for Parkinson's disease. Mov Disord 2013, 28:216-219.

70. Iranzo A, Lomena F, Stockner H, Valldeoriola F, Vilaseca I, Salamero M, Molinuevo JL, Serradell M, Duch J, Pavia J, Gallego J, Seppi K, Högl B, Tolosa E, Poewe W, Santamaria J, Sleep Innsbruck Barcelona (SINBAR) group: Decreased striatal dopamine transporter uptake and substantia nigra hyperechogenicity as risk markers of synucleinopathy in patients with idiopathic rapid-eye-movement sleep behaviour disorder: a prospective study [corrected]. Lancet Neurol 2010, 9:1070-1077.

71. Pardo JV, Lee JT, Kuskowski MA, Munch KR, Carlis JV, Sheikh SA, Surerus C, Lewis SM, McCarten JR, Fink H, McPherson S, Shah HH, Rottunda S, Dysken MW: Fluorodeoxyglucose positron emission tomography of mild cognitive impairment with clinical follow-up at 3 years. Alzheimers Dement 2010, 6:326-333.

72. Clerici F, Del Sole A, Chiti A, Maggiore L, Lecchi M, Pomati S, Mosconi L, Lucignani G, Mariani C: Differences in hippocampal metabolism between amnestic and non-amnestic $\mathrm{MCl}$ subjects: automated FDG-PET image analysis. Q J Nucl Med Mol Imaging 2009, 53:646-657.

73. Fujishiro H, Iseki E, Kasanuki K, Chiba Y, Ota K, Murayama N, Sato K: A follow up study of non-demented patients with primary visual cortical hypometabolism: prodromal dementia with Lewy bodies. J Neurol Sci 2013, 334:48-54

74. Gaenslen A, Swid I, Liepelt-Scarfone I, Godau J, Berg D: The patients' perception of prodromal symptoms before the initial diagnosis of Parkinson's disease. Mov Disord 2011, 26:653-658.

75. Postuma RB, Gagnon JF, Pelletier A, Montplaisir J: Prodromal autonomic symptoms and signs in Parkinson's disease and dementia with Lewy bodies. Mov Disord 2013, 28:597-604

76. Postuma RB, Lang AE, Gagnon JF, Pelletier A, Montplaisir JY: How does parkinsonism start? Prodromal parkinsonism motor changes in idiopathic REM sleep behaviour disorder. Brain 2012, 135:1860-1870

77. Postuma RB, Gagnon JF, Vendette M, Desjardins C, Montplaisir JY: Olfaction and color vision identify impending neurodegeneration in rapid eye movement sleep behavior disorder. Ann Neurol 2011, 69:811-818.

78. Postuma RB, Lanfranchi PA, Blais H, Gagnon JF, Montplaisir JY: Cardiac autonomic dysfunction in idiopathic REM sleep behavior disorder. Mov Disord 2010, 25:2304-2310.

79. Tanaka Y, Kato T, Nishida H, Yamada M, Koumura A, Sakurai T, Hayashi Y, Kimura A, Hozumi I, Araki H, Murase M, Nagaki M, Moriwaki H, Inuzuka T: Is there a delayed gastric emptying of patients with early-stage, untreated Parkinson's disease? An analysis using the ${ }^{13} \mathrm{C}$-acetate breath test. J Neurol 2011, 258:421-426.

80. Dubois B, Feldman HH, Jacova C, Cummings JL, Dekosky ST, Barberger-Gateau P, Delacourte A, Frisoni G, Fox NC, Galasko D, Gauthier S, Hampel H, Jicha GA, Meguro K, O'Brien J, Pasquier F, Robert P, Rossor M, Salloway S, Sarazin M, de Souza LC, Stern Y, Visser PJ, Scheltens P: Revising the definition of Alzheimer's disease: a new lexicon. Lancet Neurol 2010, 9:1118-1127.

81. Albert MS, DeKosky ST, Dickson D, Dubois B, Feldman HH, Fox NC, Gamst A, Holtzman DM, Jagust WJ, Petersen RC, Snyder PJ, Carrillo MC, Thies B, Phelps $\mathrm{CH}$ : The diagnosis of mild cognitive impairment due to Alzheimer's disease: recommendations from the National Institute on Aging-Alzheimer's Association workgroups on diagnostic guidelines for Alzheimer's disease. Alzheimers Dement 2011, 7:270-279. 
82. Postuma RB: Prodromal Parkinson's disease - using REM sleep behavior disorder as a window. Parkinsonism Relat Disord 2014, 20(Suppl 1):S1-S4.

83. Dugger BN, Boeve BF, Murray ME, Parisi JE, Fujishiro H, Dickson DW,

Ferman TJ: Rapid eye movement sleep behavior disorder and subtypes in autopsy-confirmed dementia with Lewy bodies. Mov Disord 2012, 27:72-78

84. Ferman TJ, Boeve BF, Smith GE, Lin SC, Silber MH, Pedraza O, Wszolek Z, Graff-Radford NR, Uitti R, Van Gerpen J, Pao W, Knopman D, Pankratz VS, Kantarci K, Boot B, Parisi JE, Dugger BN, Fujishiro H, Petersen RC, Dickson DW: Inclusion of RBD improves the diagnostic classification of dementia with Lewy bodies. Neurology 2011, 77:875-882.

85. Le Couteur DG, Doust J, Creasey H, Brayne C: Political drive to screen for pre-dementia: not evidence based and ignores the harms of diagnosis. BMJ 2013, 347:f5125

86. Brooker D, Fontaine JL, Evans S, Bray J, Saad K: Public health guidance to facilitate timely diagnosis of dementia: ALzheimer's COoperative Valuation in Europe recommendations. Int I Geriatr Psychiatry 2014, 29:682-693.

87. Alzheimer's Disease-Related Dementias Conference Recommendations to the NINDS Council. [http://www.ninds.nih.gov/funding/areas/ neurodegeneration/workshops/adrd2013/ADRD_2013_Report-andMemorandum_508comp.pdf]

88. Visanji NP, Brooks PL, Hazrati LN, Lang AE: The prion hypothesis in Parkinson's disease: Braak to the future. Acta Neuropathol Commun 2013, 1:2.

10.1186/alzrt274

Cite this article as: Donaghy and McKeith: The clinical characteristics of dementia with Lewy bodies and a consideration of prodromal diagnosis. Alzheimer's Research \& Therapy 2014, 6:46 